Article

\title{
The Influence of Sinusoidal Oscillating Water Flow on Sprinkler and Impact Kinetic Energy Intensities of Laterally-Moving Sprinkler Irrigation Systems
}

\author{
Kai Zhang ${ }^{1,2}$, Bo Song ${ }^{1,2}$ and Delan Zhu ${ }^{1,2, *}$ \\ 1 Key Laboratory of Agricultural Soil and Water Engineering in Arid and Semiarid Areas, \\ Ministry of Education, Northwest A\&F University, Yangling 712100, China \\ 2 College of Water Resources and Architectural Engineering, Northwest A\&F University, Yangling 712100, China \\ * Correspondence: zhudelan@nwafu.edu.cn; Tel.: +86-13992812016
}

Received: 15 April 2019; Accepted: 23 June 2019; Published: 27 June 2019

\begin{abstract}
Laterally-moving sprinkler irrigation systems under low pressure experience problems including small spraying range, low uniformity, surface runoff, and low water utilization rate. To solve these problems, experiments were carried out on a laterally-moving sprinkler irrigation system using a Nelson D3000 sprinkler (Nelson Irrigation Co., Walla Walla, WA, USA) under low pressure, sinusoidal oscillating water flow. The sprinkler intensity and impact kinetic energy intensity distribution were investigated for sprinklers both static and in motion. The test data were used to calculate combined sprinkler intensity and impact kinetic energy intensity uniformity for different nozzle spacings, and were compared with constant water pressure test results. It was found that sinusoidal oscillating water flow can effectively increase spraying range, as well as reducing the peak value of the sprinkler intensity and impact kinetic energy intensity. Within an optimal range of amplitude and nozzle spacing, sinusoidal oscillating water flow significantly improves the combined sprinkler intensity, impact kinetic energy intensity uniformity, and the spraying quality of laterally-moving sprinkler irrigation systems under low pressure conditions. When the average water pressure is $100 \mathrm{kPa}$, the optimal range of amplitude of sinusoidal oscillating flow applied to the laterally-moving sprinkler irrigation system is $50-60 \mathrm{kPa}$. When the amplitude is $50 \mathrm{kPa}$, the optimal nozzle spacing is $3.5-4 \mathrm{~m}$; when the amplitude is $60 \mathrm{kPa}$, the optimal nozzle spacing is $3.5-4.5 \mathrm{~m}$. The related parameters can provide a reference for the application of sinusoidal oscillating water flow in laterally-moving sprinkler irrigation systems.
\end{abstract}

Keywords: sinusoidal oscillating water flow; laterally-moving sprinkler irrigation systems; sprinkler intensity; impact kinetic energy intensity

\section{Introduction}

Agricultural production consumes significant water resources, and their conservation and efficiency have always been the goal of irrigation [1]. Sprinkler irrigation equipment has been widely used in various countries as it reduces labor and water, provides uniform irrigation, and results in yield increases [2-4]. Currently, high water pressure is a common problem in sprinkler irrigation equipment, associated with high energy consumption, input costs, and maintenance costs $[5,6]$. Moreover, high water pressure sprinkler irrigation equipment cannot meet the needs of some small farms or remote areas due to inadequate water supply facilities [7]. As energy costs continue to increase, more attention is being paid to the production and research of low pressure and low energy consumption sprinkler irrigation equipment. Sprinklers are a key piece of equipment that affect the irrigation quality of sprinkler systems. One of the ways to reduce the energy consumption of 
a sprinkler system is to reduce the working pressure of the sprinkler, i.e., conducting spraying at a lower pressure [8]. However, when the working pressure decreases, the sprinkler will have a shorter spraying range, uneven water distribution, and a larger peak value of sprinkler intensity. It becomes difficult to guarantee the quality of the irrigation spray $[9,10]$. Nelson, Senninger, and many other manufacturers of irrigation equipment are committed to the research and development of a variety of low-pressure sprinklers, including rocker-type, refraction-type, and some other types of sprinkler that are suitable for low water pressure [11,12]. Adding auxiliary nozzles, jet devices, and water dispersing devices, or using non-circular nozzles in place of the original nozzle, can also improve the spraying effect of the sprinkler under low pressure [13-15]. However, the research and development of low-pressure sprinklers is affected by capital and research cycles, and the improvements that can be made to the spraying effect by changing the original sprinkler structure are also very limited. Traditionally, only constant water pressure has been used in irrigation systems. In recent years, some scholars have applied dynamic water pressure in irrigation systems. When using a dynamic water pressure water supply in an irrigation system, the speed of the pump is adjusted through frequency conversion technology, so as to provide an oscillating water flow with periodic dynamic changes of wave pattern, amplitude, and average water pressure [16]. The low-pressure, sinusoidal oscillating water flow improves the sprinkler intensity distribution of the fixed sprinkler. When the same uniformity is obtained, the working pressure of a sprinkler under oscillating water flow is lower than that under constant water flow. Using oscillating water flow, a sprinkler irrigation system can reduce operation costs, and, as the cost of energy increases, the economic benefits are more pronounced $[17,18]$. The application of oscillating water flow in sprinkler irrigation also shows good prospects in reducing soil erosion caused by runoff and salt and nutrient leaching, and improving the utilization efficiency of water [19]. In recent years, the emergence of some new testing techniques has also enriched the knowledge of sprinkler irrigation technology. The study of sprinkler irrigation is not only limited to testing sprinkler intensity and other macro parameters, but is also limited by the instrument, and the size, diameter, and other micro parameters of the droplets tested. Droplet motion parameters are used to calculate the impact kinetic energy intensity of the droplets [20,21]. Impact kinetic energy intensity is the largest factor causing soil erosion, as well as an important index affecting irrigation quality and water use efficiency [22].

The above results preliminarily show that sinusoidal oscillating water flow improves the sprinkler intensity distribution of fixed sprinklers, and the results do not involve the research on impact kinetic energy intensity. However, no studies have reported the use of sinusoidal oscillating water flow in a laterally-moving sprinkler irrigation system, or the combination distribution and uniformity of sprinkler intensity and impact kinetic energy intensity. In this paper, the Nelson D3000 sprinkler, a type commonly used in laterally-moving sprinkler irrigation systems, was taken as the research object to study the combined distribution of sprinkler intensity and impact kinetic energy intensity under different amplitudes of sinusoidal oscillating water flow and different sprinkler spacings. Taking uniformity as the standard, a reasonable selection of amplitudes and spacings of sprinklers for sinusoidal oscillating water flow applied to a laterally-moving sprinkler irrigation system is put forward.

\section{Materials and Methods}

\subsection{Testing Apparatus}

The experiment was conducted at the Irrigation Hydraulics Laboratory, Northwest A\&F University, Yangling, China. The main component of the dynamic water pressure sprinkler irrigation system that was tested included a 2D video disdrometer (Joanneum Research Corp, Graz, Austria), water tank, pump, variable frequency drive (Tianshui Corp, Jiangsu, China), computer, mobile cart, Nelson D3000 sprinkler was equipped with a $7.2 \mathrm{~mm}$ diameter nozzle and a deflector plate with 36 grooves (Figure 1), pressure transducer (range 0-0.6 MPa, accuracy 0.1\%) made by Tianshui Corp, Jiangsu, China, electromagnetic flowmeter (range $0.29-28.95 \mathrm{~m}^{3} / \mathrm{h}$ ) produced by Xi'an Xinmin Electronics 
Corp, Shanxi, China, and automatic recording catch can (HOBO RG3-M type, accuracy $\pm 0.1 \%$, resolution $0.02 \mathrm{~mm}$ ) produced by Onset computer Corp, America. The pulsating pressure water was produced by an automatic pressure control system that consisted of a centrifugal pump with an electric motor, a variable frequency drive (VFD), and a programmable logic controller (PLC) produced by Xi'an Xinmin Electronics Corp, Shanxi, China. First, the program for implementing the desired pulsating pressure was uploaded to the PLC to control the VFD, which modified the pump motor speed. The model of the pulsating pressure (such as trigonometric, sinusoidal, or trapezoidal), maximum pressure, minimum pressure, and period of function for pulsating pressure can be set in the program. Second, the electric motor speed of the centrifugal pump was controlled by the VFD to produce the expected pulsating pressure. The schematic diagram of the dynamic water pressure test platform is shown in Figure 2. The sprinkler was mounted on the trolley at a height of $1.60 \mathrm{~m}$.

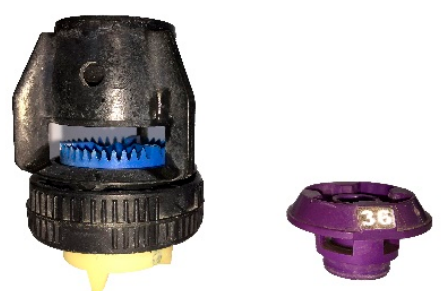

Figure 1. Nelson D3000 sprinkler.

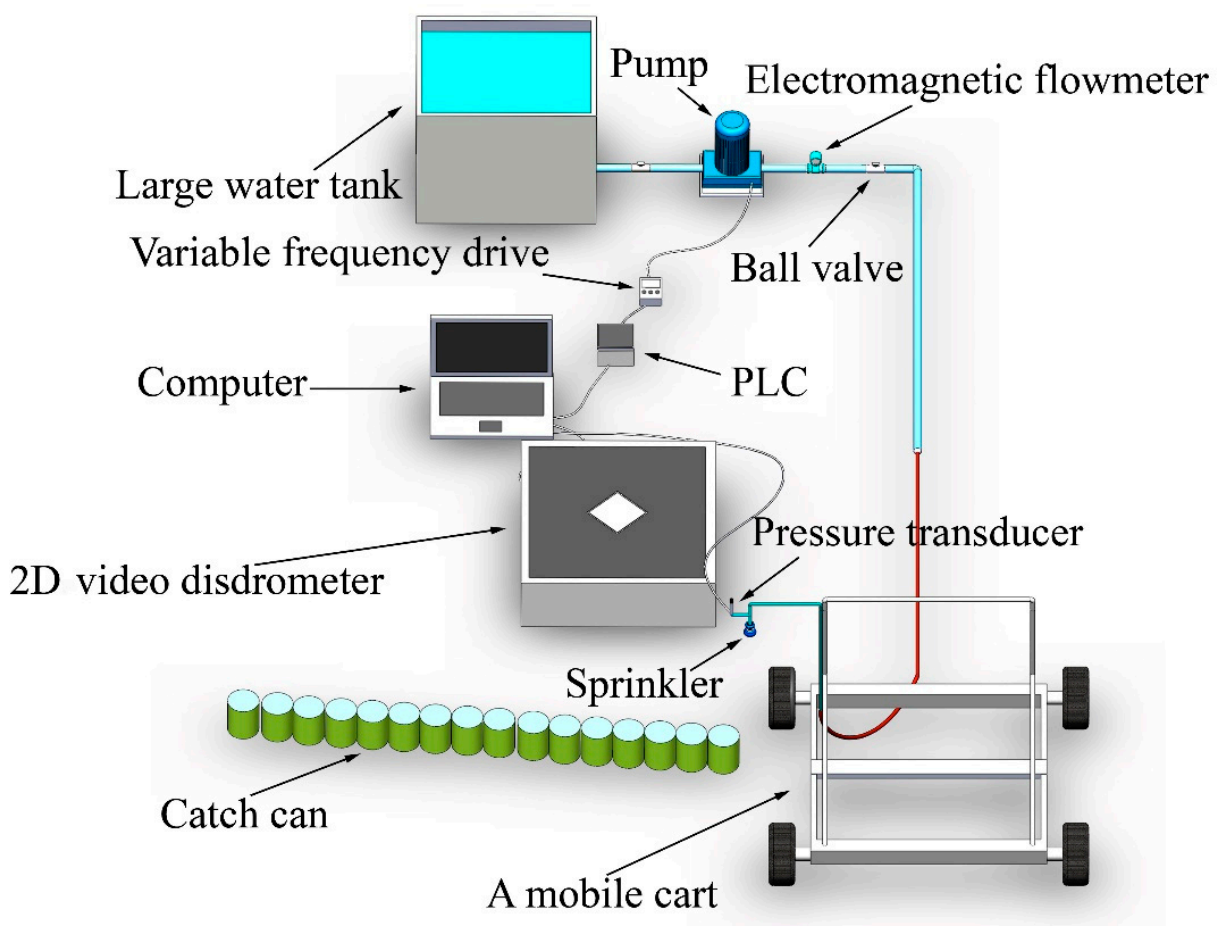

Figure 2. Dynamic water pressure test platform.

\subsection{Experimental Design and Methods}

For the dynamic water pressure change mode, a trigonometric function was selected (Figure 3), and a change period of $60 \mathrm{~s}$ was selected. The rated working pressure range of the D3000 sprinkler is $41-280 \mathrm{kPa}$. In order to study how dynamic water pressure in a low pressure environment affects the performance of the D3000 sprinkler, the average water pressure was set to $100 \mathrm{kPa}$. The dynamic pressure amplitude, i.e., the absolute difference between the extreme value and average pressure, denoted by the letter A, was $20 \mathrm{kPa}$ at the start; five amplitudes were then tested: 30, 40, 50, 60 , and $70 \mathrm{kPa}$. Subsequently, the pressure range of the sinusoidal oscillating water flow was between 
$30 \mathrm{kPa}$ and $170 \mathrm{kPa}$, which is also in line with the low pressure sprinkler pressure range [23-25]. During the experiment, the average humidity fell within the range of $39-58 \%$, whereas the average value of temperature fell within the range of $26-34^{\circ} \mathrm{C}$. Furthermore, the wind speed was less than $1 \mathrm{~m} / \mathrm{s}$.

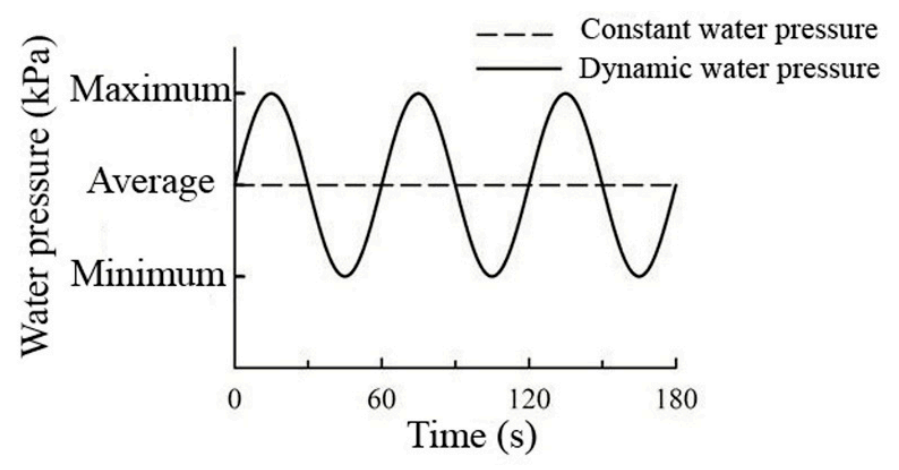

Figure 3. Sinusoidal oscillating water pressure.

2.2.1. Radial Distribution of Sprinkler Intensity and Impact Kinetic Energy Intensity under Constant and Dynamic Water Pressure

The water is ejected from the D3000 sprinkler via the flow passages, and the water in each flow passage is basically the same and is relatively independent [26]. Catch cans were arranged closely along the jet direction. The cart was stationary. After the working pressure of the nozzle was stabilized, three independent flow passages were selected for testing. The test layout is shown in Figure 4. Catch cans (height, $25.7 \mathrm{~cm}$; diameter of opening, $15.2 \mathrm{~cm}$ ) were arranged at a spacing of $0.25 \mathrm{~m}$ across the radial center of the flow passage. The number of catch cans depended on the spraying range. Each measurement time was $1 \mathrm{~h}$, and each test was repeated three times. The sprinkler intensity was the ratio of the amount of water at the measuring point to the spraying time. The sprinkler intensities of the measurement points in each test are the average value of the sprinkler intensity at the same position on three flow passages. Each test was repeated three times for an average value.

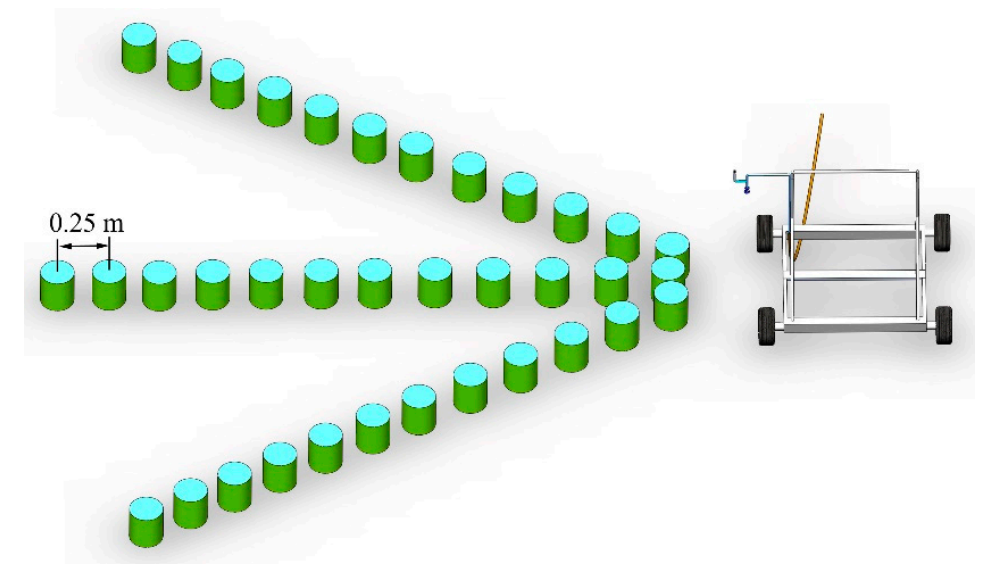

Figure 4. The test layout of radial distribution of sprinkler intensity and impact kinetic energy intensity.

The measurement points of the radial distribution of the impact kinetic energy intensity were arranged in the same way as those of the catch cans. Parameters, such as diameter and velocity of water droplets at each measurement point, were tested by $2 \mathrm{D}$ video disdrometer. Two vertically disposed CCD cameras inside the instrument made linear scans of droplets passing through the test area and 
recorded individual drop state parameter. Equation (1) was used to calculate the impact kinetic energy intensity of each measurement point [27-29].

$$
\mathrm{S}_{\mathrm{pj}}=\frac{\sum_{\mathrm{i}=1}^{\mathrm{n}} \frac{1}{12} \pi \mathrm{d}_{\mathrm{i}}^{3} \rho_{\mathrm{w}} \mathrm{v}_{\mathrm{i}}^{2}}{1000 \sum_{\mathrm{i}=1}^{\mathrm{n}} \frac{1}{6} \pi \mathrm{d}_{\mathrm{i}}^{3}} \times \frac{\mathrm{P}_{\mathrm{j}}}{3600}
$$

where $S_{p j}$ is the impact kinetic energy intensity of each measurement point $\left(W / m^{2}\right) ; n$ is the number of droplets, at least 10,000 droplets; $d_{i}$ is the measured diameter of the ith drop (mm); $\varrho_{w}$ is the mass density of water $\left(\mathrm{kg} \mathrm{m}^{-3}\right) ; \mathrm{v}_{\mathrm{i}}$ is the measured velocity of the ith drop $\left(\mathrm{m} \mathrm{s}^{-1}\right)$; and $\mathrm{P}_{\mathrm{j}}$ is the sprinkler intensity of the $j$ th catch cans $\left(\mathrm{mm} \mathrm{h}^{-1}\right)$.

\subsubsection{The Distribution of Sprinkler Intensity and Impact Kinetic Energy Intensity of a Single} Moving Sprinkler

After the working pressure of the sprinkler was stable, the cart began moving from one side of the test area, passed through the test area at a constant speed of $60 \mathrm{~m} / \mathrm{h}$, and ran to the other side of the test area until the rain gauge cylinder in the area had no sprinkler intensity at all. Each test was repeated three times, and the average value was taken. Considering that the periodic pressure change of sinusoidal oscillating water flow will lead to the change of sprinkler intensity along the direction of sprinkler movement, the width of the test area where the catch cans were placed was an integer multiple of the movement distance of the sprinkler in one cycle $(1 \mathrm{~m})$. In addition, as the sprinkler intensity distribution of the sprinkler had symmetry along the movement route of the sprinkler, the catch cans were only arranged on one side of the walking route of the sprinkler. Finally, the width of the test area was determined to be $3 \mathrm{~m}$, and the length of the test area was determined according to the spraying range. The spacing of the catch cans was $0.5 \times 0.5 \mathrm{~m}^{2}$, as shown in Figure 5 .

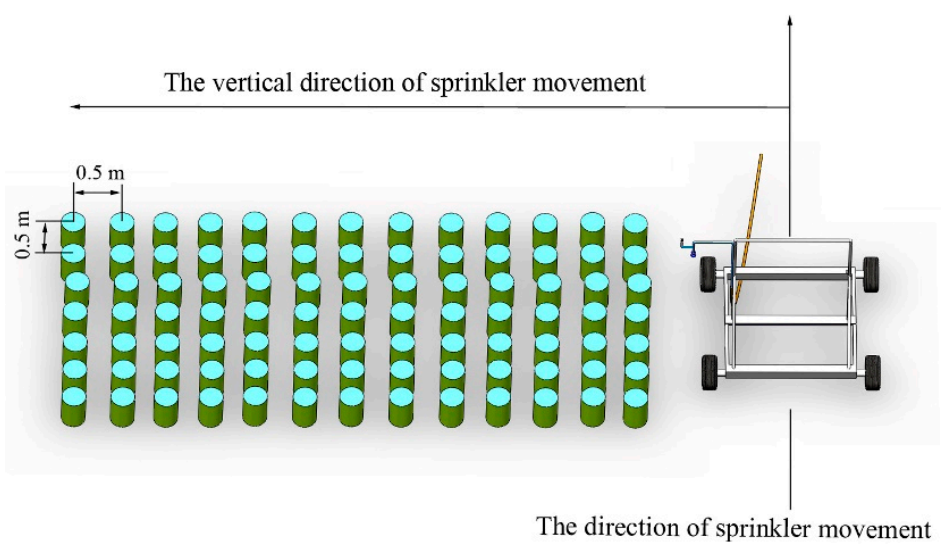

Figure 5. The test layout of a single moving sprinkler.

2.2.3. Combined Sprinkler Intensity and Impact Kinetic Energy Intensity Distribution under Different Nozzle Spacings

After obtaining the sprinkler intensity distribution data for one side of a single sprinkler, and because the distribution of the sprinkler intensity on both sides of the nozzle is symmetrical, the distribution of sprinkler intensity of a single nozzle can be obtained by mirror processing of the distribution of sprinkler intensity on one side of the nozzle. The $25 \mathrm{~m}$ laterally-moving sprinkler irrigation systems were arranged according to the spacing of sprinklers at 1.5, 2, 2.5, 3, 3.5, 4, 4.5, 5, 6 , and $6.5 \mathrm{~m}$. The number of sprinklers under the corresponding spacing was $17,13,11,9,8,7,6,6$, 5 , and 4, respectively. Figure 6 shows the schematic diagram of the sprinkler layout and sprinkler intensity superposition process when the sprinkler spacing is $5 \mathrm{~m}$. The letters a-f in the figure represent the six sprinklers arranged equidistance from left to right on the plane. The sprinkler intensity data of a single sprinkler were processed in a grid. The area of each grid was $0.5 \times 0.5 \mathrm{~m}$. The sprinkler 
intensity of a measured point in each grid was used to represent the sprinkler intensity of each grid. As shown in Figure 6, when calculating the sprinkler intensity of grid h1, h2, and h3 in the third column on the right of sprinkler $\mathrm{f}$, the sprinkler intensity needs to be superimposed on grids $\mathrm{h} 1, \mathrm{~h} 2$, and $\mathrm{h} 3$, including the sprinkler intensity of $\mathrm{f} 1, \mathrm{f} 2$, and $\mathrm{f} 3$ of sprinkler $\mathrm{f}$, and e1, e2, and e3 of sprinkler e. According to this process, the sprinkler intensity of each grid in the spraying area was superimposed and calculated, and the sprinkler intensity distribution of the whole machine combination was finally obtained [30]. The calculation method of the combined impact kinetic energy intensity is the same as that of the combined sprinkler intensity.

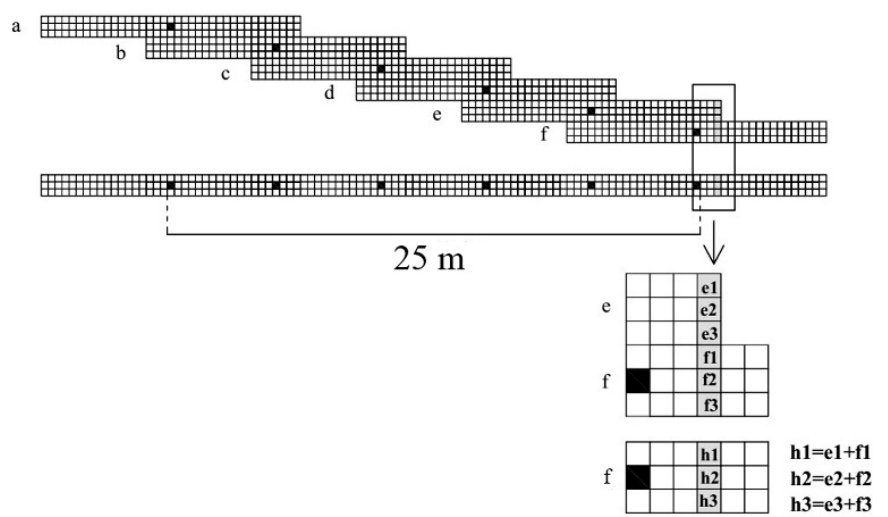

Figure 6. Calculation diagram of the distribution of combined sprinkler intensity. Sprinklers are spaced $5 \mathrm{~m}$ apart.

\section{Results}

\subsection{Radial Distribution of Sprinkler Intensity and Impact Kinetic Energy Intensity under Constant and} Dynamic Water Pressure

Figure 7 shows the radial distribution of water and impact kinetic energy intensity under oscillating pressure with different amplitudes. The figure clearly shows that the spraying range under constant water pressure is short. The water distribution that presents the thin-high triangular shape is uneven and concentrated, and the peak value of the sprinkler intensity is large. Compared to the situation of constant water pressure, sinusoidal oscillating water flow can effectively increase the spraying range and reduce the peak value of sprinkler intensity. Because of the constant water pressure, the nozzle jet fragmentation is not sufficient, and the main jet distribution covers a very small limited area. However, the pressure at the outlet of the nozzle under oscillating water pressure is periodic, and the spraying range also changes periodically, so that the mainstream of the jet uniformly sweeps over a wide area between the sprinkler intensity maximum and the sprinkler intensity minimum range. Table 1 shows that when the amplitude increased from $0 \mathrm{kPa}$ to $70 \mathrm{kPa}$, the spraying range increased from $7 \mathrm{~cm}$ to $9.75 \mathrm{~cm}$, an increase of $39 \%\left(39 \% \approx \frac{9.75-7}{7} \times 100 \%\right)$. When the amplitude increased from $0 \mathrm{kPa}$ to $60 \mathrm{kPa}$, the coefficient of variation $(\mathrm{CV})$ of sprinkler intensity decreased from $122 \%$ to $43 \%$, a decrease of $79 \%$. When the amplitude increased from $60 \mathrm{kPa}$ to $70 \mathrm{kPa}$, the CV of sprinkler intensity increased from $43 \%$ to $48 \%$, an increase of $5 \%$. When the amplitude increased from $0 \mathrm{kPa}$ to $60 \mathrm{kPa}$, the peak value of sprinkler intensity decreased from $219 \mathrm{~mm} / \mathrm{h}$ to $52 \mathrm{~mm} / \mathrm{h}$, a decrease of $76 \%$. When the amplitude increased from $60 \mathrm{kPa}$ to $70 \mathrm{kPa}$, the peak value of sprinkler intensity increased from $52 \mathrm{~mm} / \mathrm{h}$ to $57 \mathrm{~mm} / \mathrm{h}$, an increase of $10 \%$. It can be seen that the improvement effect of spraying is limited by the increase of amplitude. In a certain amplitude range (0-60 $\mathrm{kPa})$, the increase of amplitude can improve the spraying effect. 


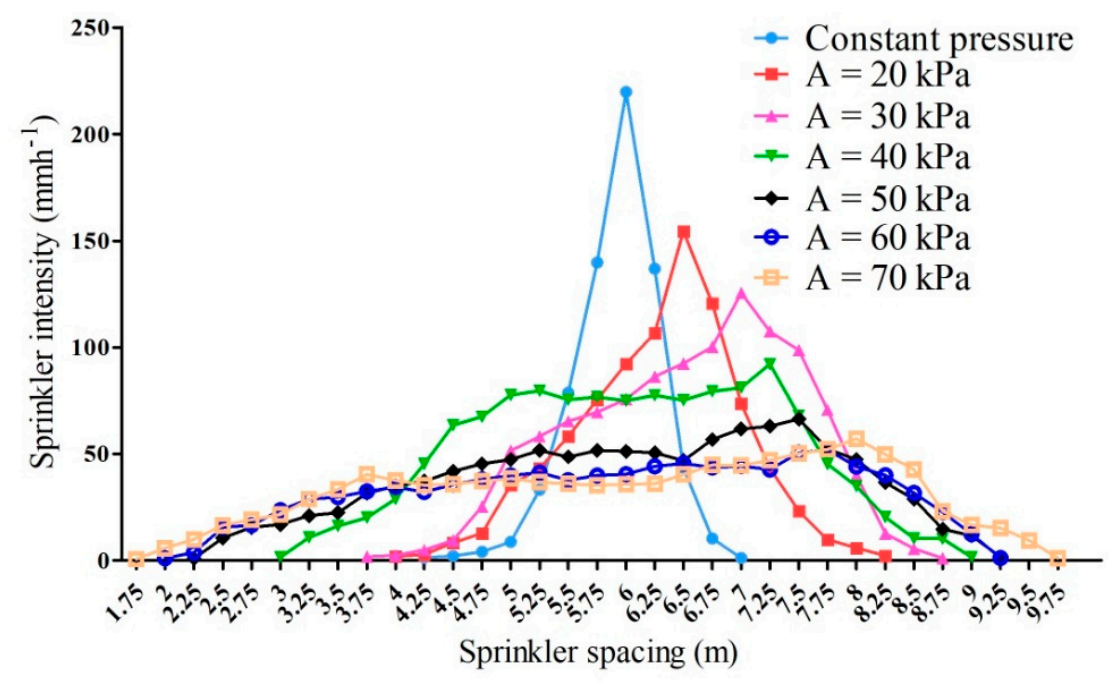

(a) The radial distribution of sprinkler intensity under constant and dynamic water pressure

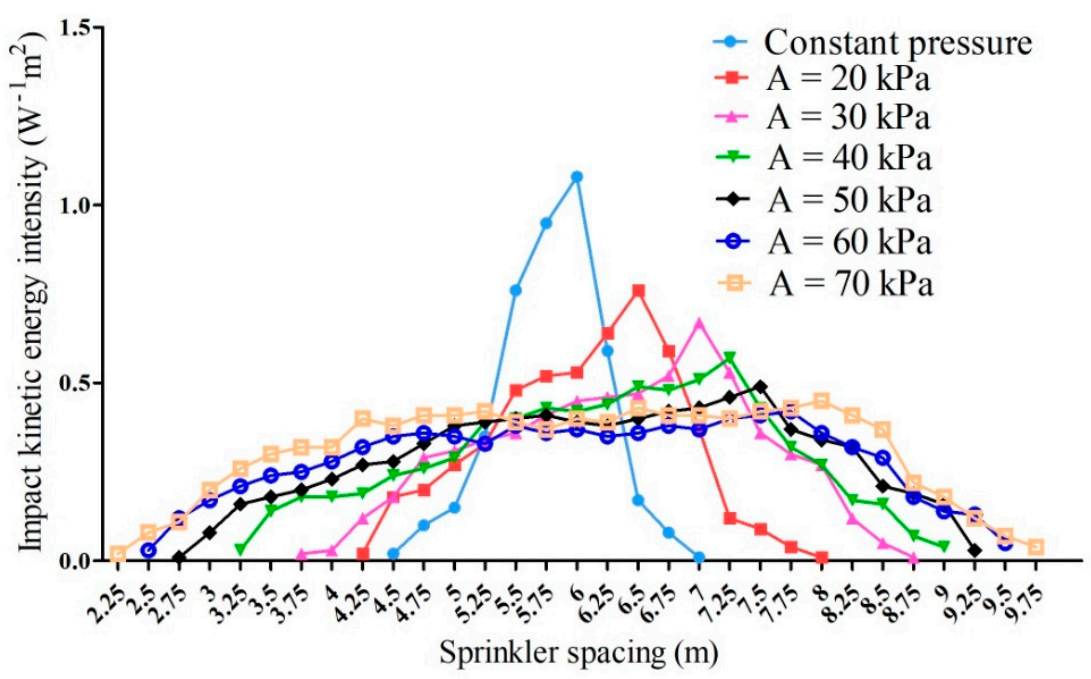

(b) The radial distribution of impact kinetic energy intensity under constant and dynamic water pressure

Figure 7. The radial distribution of sprinkler intensity (a) and impact kinetic energy intensity (b) under constant and dynamic water pressure. The average water pressure is $100 \mathrm{kPa}$.

Table 1. The testing parameter of radial distribution of sprinkler intensity and impact kinetic energy intensity under constant and dynamic water pressure.

\begin{tabular}{cccccc}
\hline $\begin{array}{c}\text { Amplitudes } \\
\mathbf{( k P a )}\end{array}$ & $\begin{array}{c}\text { Spraying } \\
\text { Range (m) }\end{array}$ & $\begin{array}{c}\text { The CV of } \\
\text { Sprinkler } \\
\text { Intensity (\%) }\end{array}$ & $\begin{array}{c}\text { The Peak Value of } \\
\text { Sprinkler Intensity } \\
\mathbf{( m m} / \mathbf{h})\end{array}$ & $\begin{array}{c}\text { The CV of Impact } \\
\text { Kinetic Energy } \\
\text { Intensity } \mathbf{( \% )}\end{array}$ & $\begin{array}{c}\text { The Peak Value of } \\
\text { Impact Kinetic Energy } \\
\text { Intensity }\left(\mathbf{W} / \mathbf{m}^{\mathbf{2}}\right)\end{array}$ \\
\hline Constant & 7 & 122 & 219 & 97 & 1.08 \\
pressure & 8.25 & 93 & 154 & 73 & 0.76 \\
$\mathrm{~A}=20$ & 8.75 & 76 & 125 & 62 & 0.67 \\
$\mathrm{~A}=30$ & 9 & 61 & 92 & 52 & 0.57 \\
$\mathrm{~A}=40$ & 9.25 & 50 & 66 & 45 & 0.49 \\
$\mathrm{~A}=50$ & 9.25 & 43 & 52 & 38 & 0.42 \\
$\mathrm{~A}=60$ & 9.75 & 48 & 57 & 44 & 0.45 \\
$\mathrm{~A}=70$ & & &
\end{tabular}


It can also be seen from Figure 7 that oscillating water pressure greatly improves the distribution of the impact kinetic energy intensity. The impact kinetic energy intensity distribution of oscillating water pressure is more uniform than constant pressure, and the peak value of the impact kinetic energy intensity of oscillating water pressure is lower than constant pressure. When the amplitude increased from $0 \mathrm{kPa}$ to $60 \mathrm{kPa}$, the $\mathrm{CV}$ of the impact kinetic energy intensity decreased from $97 \%$ to $38 \%$, a decrease of $59 \%$. When the amplitude increased from $60 \mathrm{kPa}$ to $70 \mathrm{kPa}$, the $\mathrm{CV}$ of the impact kinetic energy intensity increased from $38 \%$ to $44 \%$, an increase of $6 \%$. When the amplitude increased from $0 \mathrm{kPa}$ to $60 \mathrm{kPa}$, the peak value of the impact kinetic energy intensity decreased from $1.08 \mathrm{~W} / \mathrm{m}^{2}$ to $0.42 \mathrm{~W} / \mathrm{m}^{2}$, a decrease of $61 \%$. When the amplitude increased from $60 \mathrm{kPa}$ to $70 \mathrm{kPa}$, the peak value of the impact kinetic energy intensity increased from $0.42 \mathrm{~W} / \mathrm{m}^{2}$ to $0.45 \mathrm{~W} / \mathrm{m}^{2}$, an increase of $7 \%$. The sprinkler intensity and impact kinetic energy intensity are two different test indexes for the spraying effect of oscillating water flow. The sprinkler intensity can be directly measured. The impact kinetic energy intensity cannot be directly measured, so it is calculated through water drop motion parameters. However, the sprinkler intensity and impact kinetic energy intensity affect each other. The sprinkler intensity in a certain area is composed of countless droplets. The motion state of the droplets not only affects the impact kinetic energy intensity but also the sprinkler intensity. Therefore, the areas of high impact kinetic energy intensity are also those of high sprinkler intensity, and the distribution of sprinkler intensity is the same as the distribution of the high impact kinetic energy intensity.

\subsection{The Distribution of Sprinkler Intensity and Impact Kinetic Energy of a Single Moving Sprinkler}

Figure 8 shows the distribution of sprinkler intensity and impact kinetic energy intensity of a single moving sprinkler. It can be seen from the figure that under constant and dynamic water pressure, existing areas with high irrigation intensity and impact kinetic energy intensity exist below the sprinkler and at the end of the spraying range. However, there were areas with low sprinkler intensity and impact kinetic energy intensity near the sprinkler, and parts of the areas with low sprinkler intensity and impact kinetic energy intensity, as well as some with no distribution of sprinkler intensity and impact kinetic energy intensity. The distribution of sprinkler intensity and impact kinetic energy intensity under constant water pressure did not change much along the direction of sprinkler movement, while the distribution of sprinkler intensity and impact kinetic energy intensity under oscillating water flow changed periodically along the direction of sprinkler movement, which was related to the cyclical change of oscillating water flow. In the range of $0-60 \mathrm{kPa}$, with the increase in the amplitude, the areas of high sprinkler intensity and impact kinetic energy intensity under the sprinkler kept shrinking, and the peak value of sprinkler intensity and impact kinetic energy intensity kept weakening. At the end of the sprinkler spraying range, the area of high sprinkler intensity and impact kinetic energy intensity kept shrinking and moving towards the sprinkler, and the peak value of sprinkler intensity and impact kinetic energy intensity kept weakening. The area of low sprinkler intensity and impact kinetic energy intensity that was near the sprinkler decreased gradually. The distribution of sprinkler intensity and impact kinetic energy intensity at $70 \mathrm{kPa}$ did not improve. 

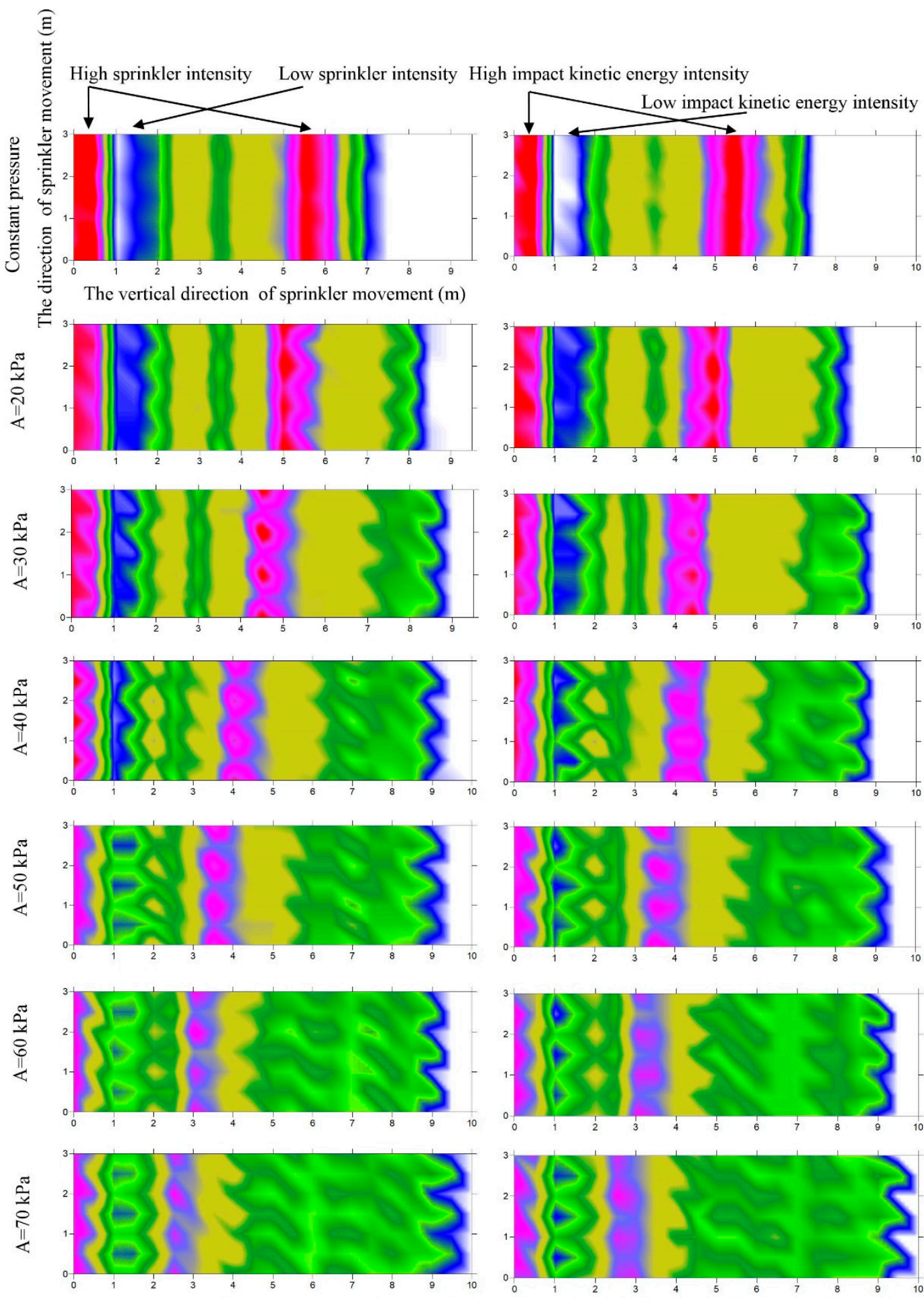

11010510095908580757065605550454035302520151050

Sprinkler intensity $\left(\mathrm{mmh}^{-1}\right)$
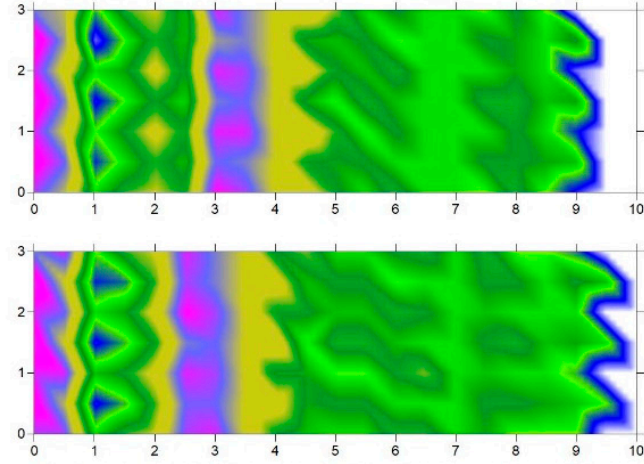

0.340 .320 .30 .280 .260 .240 .220 .20 .180 .160 .140 .120 .10 .080 .060 .040 .020

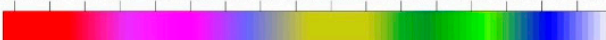

Impact kinetic energy intensity $\left(\mathrm{W}^{-1} \mathrm{~m}^{2}\right)$

Figure 8. The distribution of sprinkler intensity and impact kinetic energy intensity of a single moving sprinkler.

\subsection{The Peak Value of Combined Sprinkler Intensity and Impact Kinetic Energy Intensity}

It can be seen from Figure 9 that when the water pressure was the same, the peak value of the sprinkler intensity and impact kinetic energy intensity decreased with increased sprinkler spacing. 
When the distance between sprinklers was the same, the peak value of sprinkler intensity and impact kinetic energy intensity decreased with the increase of amplitude in the range of 0-60 kPa. With the increase of amplitude in the range of $60-70 \mathrm{kPa}$, the peak value of sprinkler intensity and impact kinetic energy intensity increased accordingly, which is similar to the radial distribution pattern of sprinkler intensity and impact kinetic energy intensity in the range of 60-70 kPa.

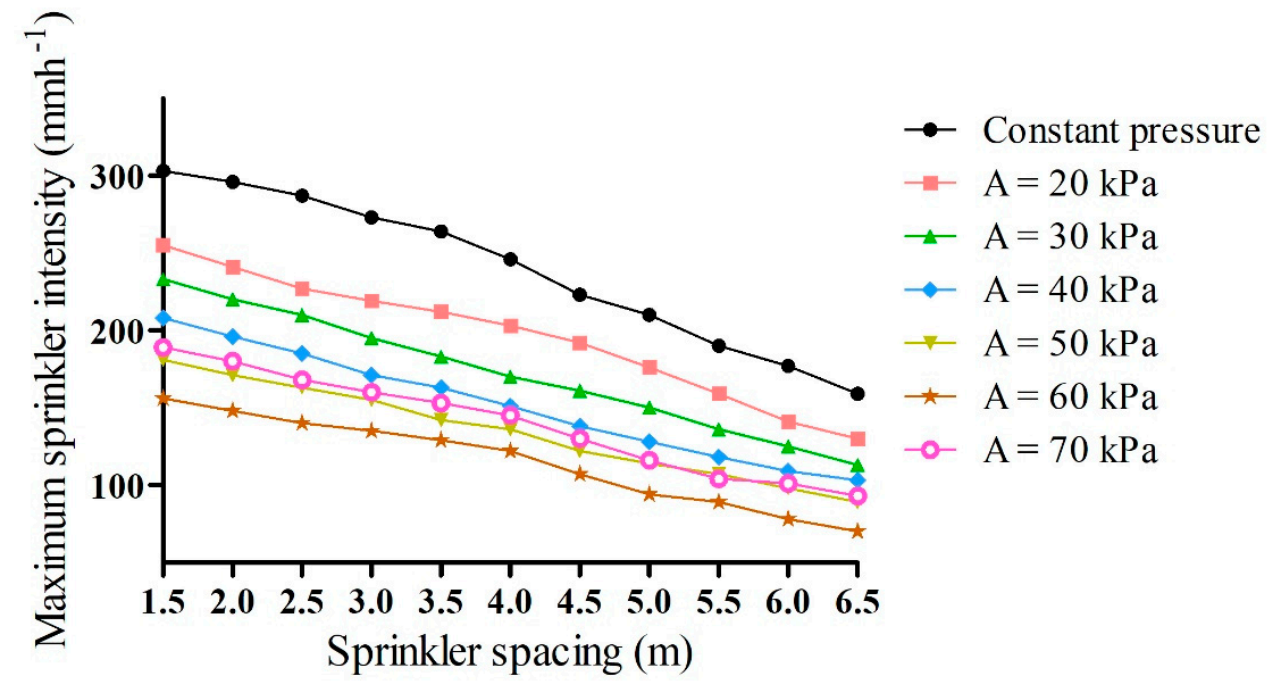

(a) The peak value of combined sprinkler intensity

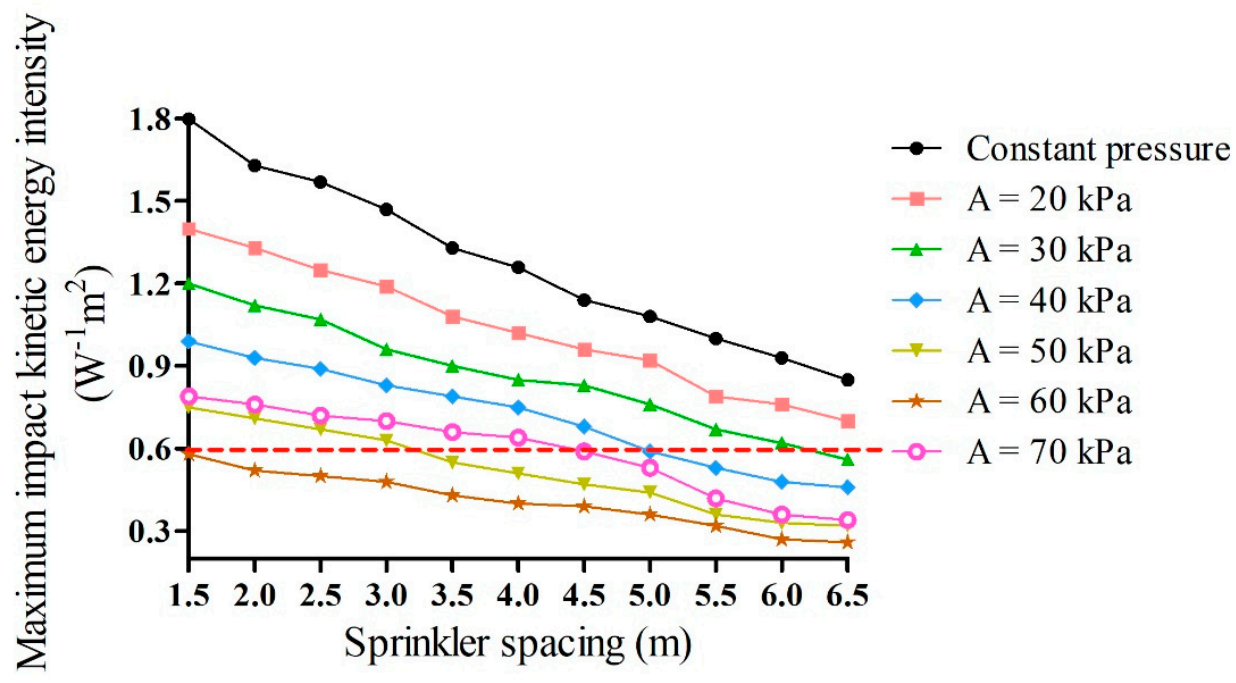

\section{(b) The peak value of combined impact kinetic energy intensity}

Figure 9. The peak value of combined sprinkler intensity (a) and impact kinetic energy intensity (b).

\subsection{The Uniformity of Combined Sprinkler Intensity and Impact Kinetic Energy Intensity}

The Christiansen uniformity coefficient $(\mathrm{Cu})$ is a commonly used indicator in sprinkler irrigation water application uniformity assessment [31]. After obtaining the combined distribution data of 
sprinkler intensity and impact kinetic energy intensity, the $\mathrm{Cu}$ of sprinkler intensity and impact kinetic energy intensity is calculated using Equations (2) and (3).

$$
\mathrm{Cu}=\left(1-\frac{\sum_{\mathrm{i}=1}^{\mathrm{n}}\left|\mathrm{h}_{\mathrm{i}}-\mathrm{h}\right|}{\mathrm{nh}}\right) \times 100 \%
$$

where $\mathrm{Cu}$ is the Christiansen uniformity coefficient of sprinkler intensity; $\mathrm{n}$ is the total number of catch cans; $h_{i}$ is the measured sprinkler intensity from an individual catch can $\left(\mathrm{mm} \mathrm{h}^{-1}\right)$; and $\mathrm{h}$ is the average measured sprinkler intensity of all catch cans $\left(\mathrm{mm} \mathrm{h}^{-1}\right)$.

$$
\mathrm{Cu}_{\mathrm{sp}}=\left(1-\frac{\sum_{\mathrm{i}=1}^{\mathrm{n}}\left|\mathrm{S}_{\mathrm{i}}-\mathrm{S}\right|}{\mathrm{nS}}\right) \times 100 \%
$$

where $\mathrm{Cu}_{\mathrm{sp}}$ is the Christiansen uniformity coefficient of the impact kinetic energy intensity; $\mathrm{n}$ is the total number of measure points; $S_{i}$ is the calculated impact kinetic energy intensity from an individual test point $\left(\mathrm{W} / \mathrm{m}^{2}\right)$; and $\mathrm{S}$ is the average calculated impact kinetic energy intensity of all test points $\left(\mathrm{W} / \mathrm{m}^{2}\right)$.

Figure 10 shows the uniformity of sprinkler intensity and impact kinetic energy intensity with sprinkler spacing under different amplitudes. The uniformity of sprinkler intensity and impact kinetic energy intensity was relatively high when the sprinkler spacing is small. With the increase in distance between sprinklers, the uniformity of sprinkler intensity and impact kinetic energy intensity decreased. When the distance between sprinklers increased to a certain distance, the uniformity of sprinkler intensity and impact kinetic energy intensity increased. Finally, the uniformity of sprinkler intensity and impact kinetic energy intensity decreased with increased nozzle spacing. When the distance between sprinklers was small, the effect of amplitude on the uniformity of sprinkler intensity and impact kinetic energy intensity was not noticeable. The uniformity of low amplitude sprinkler intensity and impact kinetic energy intensity was even higher than that of high amplitude sprinkler intensity and impact kinetic energy intensity under certain small spacing intervals. Although the spraying quality of a single sprinkler with high amplitude, described above, was higher than that of a single sprinkler with low amplitude, the poor spraying quality of a single sprinkler can be improved by the superposition of sprinkler intensity and impact kinetic energy intensity of multiple sprinklers, due to the strong interaction between sprinklers when the sprinkler spacing is small. With the increase of the distance between sprinklers, the interaction between sprinklers weakened. The improved effect of increasing amplitude on the uniformity of sprinkler intensity and impact kinetic energy intensity was gradually enhanced. The difference in the uniformity of sprinkler intensity and impact kinetic energy intensity under different amplitudes became more and more noticeable. 


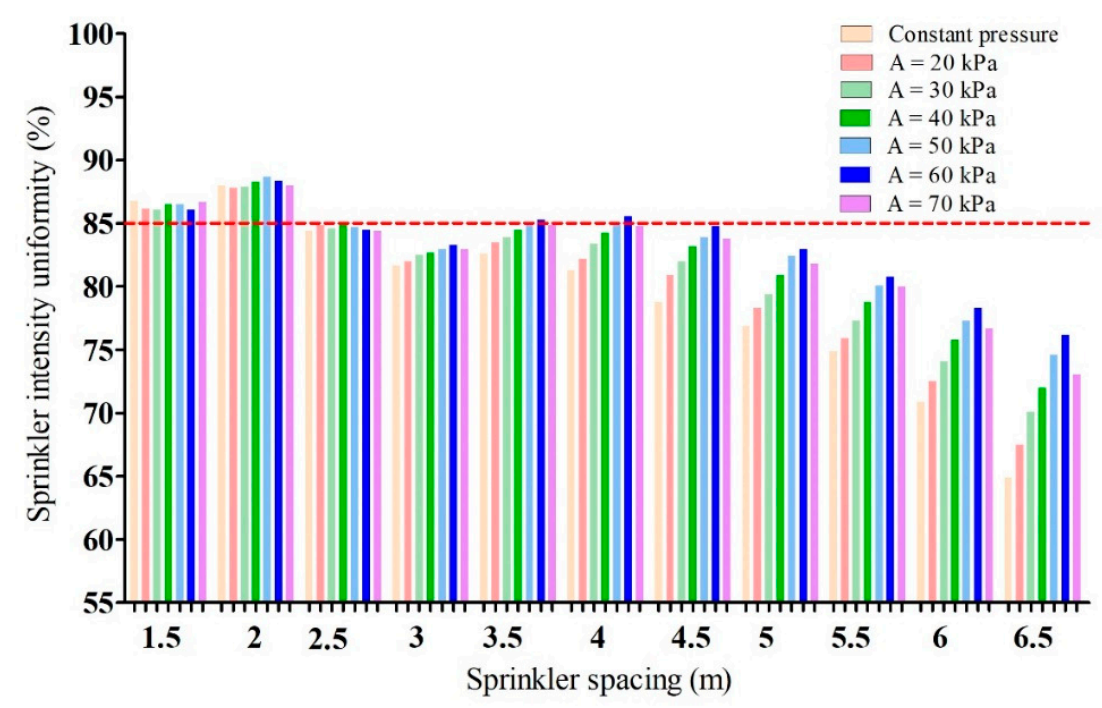

(a) Sprinkler intensity uniformity with different spacing combinations

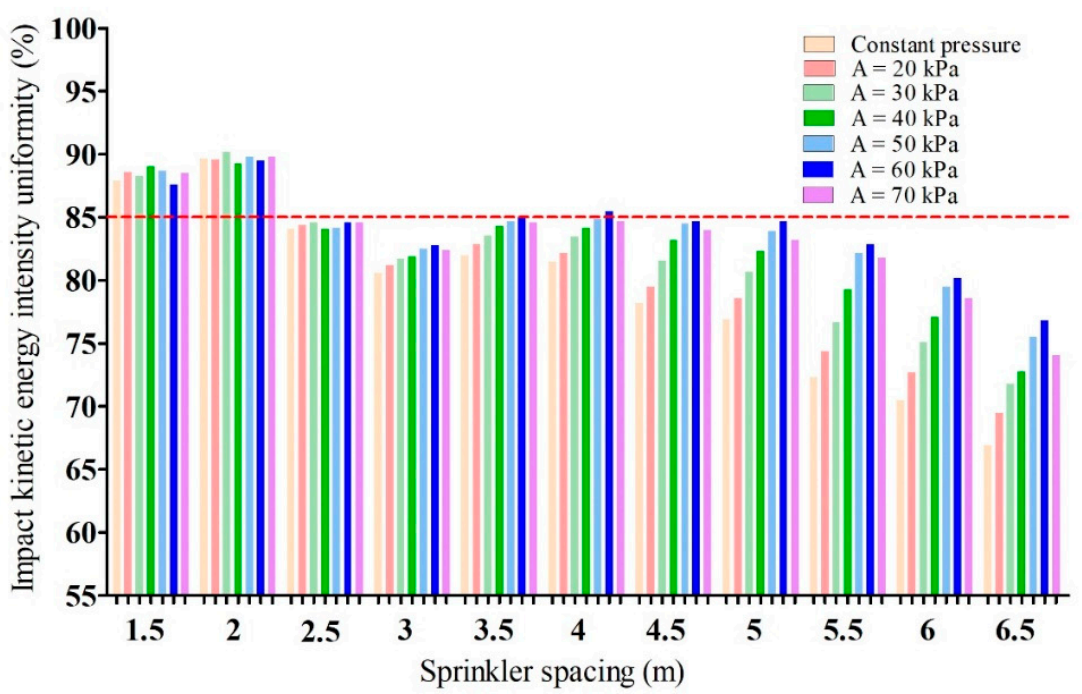

(b) Impact kinetic energy intensity uniformity with different spacing combinations

Figure 10. Sprinkler intensity (a) and impact kinetic energy intensity (b) uniformity with different spacing combinations.

The uniformity of sprinkler intensity and impact kinetic energy intensity was higher when the distance between sprinklers was smaller, and sprinkler intensity and impact kinetic energy intensity were higher. However, when impact kinetic energy intensity was greater than $0.6 \mathrm{~W} / \mathrm{m}^{2}$, the water drops reached the rainstorm level of natural precipitation, and, under such conditions, the water drops will have a greater impact on the surface soil. High impact kinetic energy intensity easily creates soil particles. Soil particles plug the pores, reduce the infiltration rate and cause surface crust, easily causing surface runoff. At the same time, areas with high impact kinetic energy intensity are often accompanied by high precipitation intensity, which also promotes the generation of surface runoff and water accumulation in local low-lying areas [32-34]. Therefore, sprinkler spacing should not be too small. When the distance between sprinklers is too large, the uniformity of sprinkler intensity and impact kinetic energy intensity is low. The uniformity will affect crop yield [35-40], and the uneven distribution of water will easily cause surface runoff [41], resulting in uneven soil 
water distribution [42], causing deep soil leakage and soil nutrient leaching [43], and thus resulting in the waste of irrigation water and energy [44]. Therefore, the distance between sprinklers should not be too large.

According to the standards of relevant studies, the uniformity is required to be greater than $85 \%$ [45], and the spacing between constant water pressure sprinklers should not exceed $2.5 \mathrm{~m}$ to meet the requirements of sprinkler intensity and impact kinetic energy intensity uniformity. However, the impact kinetic energy intensity is far higher than $0.6 \mathrm{~W} / \mathrm{m}^{2}$ (Figure 9), which easily results in runoff. When the amplitude of sinusoidal oscillating water flow was $50 \mathrm{kPa}$, the sprinklers with sprinkler intensity distribution uniformity greater than $85 \%$ were reasonably spaced at $3.5-4 \mathrm{~m}$, and the sprinklers with impact kinetic energy intensity distribution uniformity greater than $85 \%$ were reasonably spaced at $3.5-4.5 \mathrm{~m}$. Therefore, the reasonable spacing of sprinklers to meet the uniformity requirement is $3.5-4 \mathrm{~m}$, and the impact kinetic energy intensity of sprinklers is less than $0.6 \mathrm{~W} / \mathrm{m}^{2}$ (Figure 9), which makes it difficult to generate runoff. When the amplitude of sinusoidal oscillating water flow was $60 \mathrm{kPa}$, the sprinklers with sprinkler intensity distribution uniformity greater than $85 \%$ were reasonably spaced at $3.5-4.5 \mathrm{~m}$, and the sprinklers with impact kinetic energy intensity distribution uniformity greater than $85 \%$ were reasonably spaced at $3.5-5 \mathrm{~m}$. Therefore, the reasonable spacing of sprinklers to meet the uniformity requirement is $3.5-4.5 \mathrm{~m}$, and the impact kinetic energy intensity of sprinklers is less than $0.6 \mathrm{~W} / \mathrm{m}^{2}$ (Figure 9), which makes it difficult to generate runoff. When the amplitude of sinusoidal oscillating water flow was $70 \mathrm{kPa}$, the uniformity of sprinkler intensity and impact kinetic energy intensity reached $85 \%$ when the sprinkler spacing was $3.5-4 \mathrm{~m}$, but the uniformity of $70 \mathrm{kPa}$ was not as high as the uniformity of $60 \mathrm{kPa}$; the maximum power of the pump needed to be increased, and the striking kinetic energy intensity was higher than $0.6 \mathrm{~W} / \mathrm{m}^{2}$ (Figure 9). Therefore, it is not recommended to operate sinusoidal oscillating water flow in laterally-moving sprinkler irrigation systems at $70 \mathrm{kPa}$ amplitude.

\section{Discussion}

In this paper, low pressure, sinusoidal oscillating water flow was experimentally applied to laterally-moving sprinkler irrigation systems. The results show that the low pressure, sinusoidal oscillating water flow can solve the problems of small spraying range, low uniformity, surface runoff, and low utilization rate of water. All the experiments in this study were carried out indoors. Similar to other studies regarding indoor sprinkler irrigation experiments, the influence of environmental factors on sprinkler irrigation was not fully considered in this work. However, the impact of environmental factors on sprinkler irrigation cannot be ignored. Some studies have shown that wind speed, humidity, and other environmental factors can affect the distribution of sprinkler intensity of a single sprinkler, and reduce its uniformity. Among them, the influence of wind on the sprinkler intensity and sprinkler intensity uniformity of single sprinkler is significant, especially when the wind speed is large. However, it is not ideal to apply sprinkler irrigation in windy weather. Furthermore, the influence of wind on the sprinkler intensity uniformity of sprinkler irrigation systems composed of multiple sprinklers and represented by laterally-moving sprinkler irrigation systems is not significant. This was due to the superposition of the distribution of sprinkler intensity of multiple sprinklers, which reduces the influence of wind on the sprinkler intensity uniformity of sprinkler irrigation systems [30,46-52]. At present, the relevant research is concerned with using constant water pressure to carry out experiments.

Most research has focused on the influence of wind on the sprinkler intensity and the sprinkler intensity uniformity of single sprinkler or sprinkler irrigation systems composed of multiple sprinklers. However, the influence of wind on the sprinkler intensity and the impact kinetic energy intensity of single sprinkler and sprinkler irrigation systems under low pressure, sinusoidal oscillating water flow is still unclear. Therefore, related follow-up research is of great significance for the application of low pressure, sinusoidal oscillating water flow in sprinkling irrigation. 


\section{Conclusions}

In this study, experiments were carried out on a laterally-moving sprinkler irrigation system under low pressure, sinusoidal oscillating water flow. Low pressure, sinusoidal oscillating water flow can significantly improve the distribution of sprinkler intensity and the impact kinetic energy intensity of a single sprinkler. The spraying range basically increased with the increase of amplitude. Within a certain amplitude range $(0-60 \mathrm{kPa})$, both the $\mathrm{CV}$ of sprinkler intensity and impact kinetic energy intensity, and the peak values of sprinkler intensity and impact kinetic energy intensity decreased with the increase of amplitude. With the increase of amplitude, the high sprinkler intensity and impact kinetic energy intensity areas at the end of the spraying range gradually approached the sprinkler. The sprinklers spacing affected the uniformity of lateral moving sprinkler irrigation systems composed of multiple sprinklers. In laterally-moving sprinkler irrigation systems, the uniformity of sprinkler intensity and impact kinetic energy intensity should be no less than $85 \%$, and the impact kinetic energy intensity should be no higher than $0.6 \mathrm{~W} / \mathrm{m}^{2}$. In order to meet this standard, the amplitude of sinusoidal oscillating water pressure in laterally-moving sprinkler irrigation systems ranged from $50 \mathrm{kPa}$ to $60 \mathrm{kPa}$. When the amplitude of sinusoidal oscillating water flow was $50 \mathrm{kPa}$, the optimal sprinkler spacing was 3.5-4 m; when the amplitude of sinusoidal oscillating water flow was $60 \mathrm{kPa}$, the optimal sprinkler spacing was $3.5-4.5 \mathrm{~m}$. However, the influence of wind on the sprinkler intensity and the impact kinetic energy intensity of single sprinkler and sprinkler irrigation systems under low pressure, sinusoidal oscillating water flow was not considered in this study. Follow-up research will be very important for the application of low pressure, sinusoidal oscillating water flow in sprinkling irrigation.

Author Contributions: Established the theoretical basis, K.Z.; Writing, original draft preparation, K.Z.; Writing, review and editing, K.Z.; Investigation, B.S.; Supervision \& funding acquisition, D.Z.

Funding: This work was supported by [National Science-technology Support Plan Projects] grant number (2015BAD22B01-02), [State Foreign Expert Bureau “111" Project] grant number (B12007) and [Major Projects of Industry-University-Research-Application Collaborative Innovation in YangLing Demonstration Area] grant number (2017CXY-09).

Acknowledgments: We thank LetPub (www.letpub.com) for its linguistic assistance during the preparation of this manuscript.

Conflicts of Interest: The authors declare no conflict of interest.

\section{References}

1. Gan, L.; Rad, S.; Chen, X.B.; Fang, R.J.; Yan, L.; Su, S.H. Clock hand lateral, a new layout for semi-permanent sprinkler irrigation system. Water 2018, 10, 767. [CrossRef]

2. Kincaid, D.C. Application rates from center pivot irrigation with current sprinkler types. Appl. Eng. Agric. 2005, 21, 605-610. [CrossRef]

3. Evans, R.G.; King, B.A. Site-specific sprinkler irrigation in a water-limited future. Trans. ASABE 2012, 55, 493-504. [CrossRef]

4. Zhang, Y.S.; Sun, B.; Fang, H.Y.; Zhu, D.L.; Yang, L.X.; Li, Z.S. Experimental and simulation investigation on the kinetic energy dissipation rate of a fixed spray-plate sprinkler. Water 2018, 10, 1365. [CrossRef]

5. Kranz, W.L.; Eisenhauer, D.E.; Retka, M.T. Water and energy-conservation using irrigation scheduling with center-pivot irrigation systems. Agric. Water Manag. 1992, 22, 325-334. [CrossRef]

6. O'Shaughnessy, S.A.; Evett, S.R.; Andrade, M.A.; Workneh, F.; Price, J.A.; Rush, C.M. Site-specific variable-rate irrigation as a means to enhance water use efficiency. Trans. ASABE 2016, 59, 239-249.

7. Singh, A.K.; Sharma, S.P.; Upadhyaya, A.; Rahman, A.; Sikka, A.K. Performance of low energy water application device. Water Resour. Manag. 2010, 24, 1353-1362. [CrossRef]

8. Dukes, M.D.; Perry, C. Uniformity testing of variable-rate center pivot irrigation control systems. Precis. Agric. 2006, 7, 205-218. [CrossRef]

9. Sayyadi, H.; Nazemi, A.H.; Sadraddini, A.A.; Delirhasannia, R. Characterising droplets and precipitation profiles of a fixed spray-plate sprinkler. Biosyst. Eng. 2014, 119, 13-24. [CrossRef] 
10. Seginer, I.; Kantz, D.; Nir, D. The distortion by wind of the distribution patterns of single sprinklers. Agric. Water Manag. 1991, 19, 341-359. [CrossRef]

11. Hanson, B.R.; Orloff, S.B. Rotator nozzles more uniform than spray nozzles on center-pivot sprinklers. Calif. Agric. 1996, 50, 32-35. [CrossRef]

12. Ribeiro, M.S.; Lima, L.A.; Colombo, A.; Caldeira, A.C.D.M.; Faria, F.H.D.S. Water distribuition characteristics and soil loss of LEPA Quad-Spray emitter nozzles. Eng. Agric. 2013, 33, 223-236. [CrossRef]

13. Liu, J.; Yuan, S.; Li, H.; Zhu, X. Combination uniformity improvement of impact sprinkler. Trans. Chin. Soc. Agric. Eng. 2011, 27, 107-111.

14. Li, H.; Jiang, Y.; Xu, M.; Li, Y.; Chen, C. Effect on hydraulic performance of low-pressure sprinkler by an intermittent water dispersion device. Trans. ASABE 2016, 59, 521-532.

15. Yuan, S.; Wei, Y.; Li, H.; Xiang, Q. Structure design and experiments on the water distribution of the variable-rate sprinkler with non-circle nozzle. Trans. Chin. Soc. Agric. Eng. 2010, 26, 149-153.

16. Zhang, L.; Wu, P.; Zhu, D.; Zheng, C. Effect of pulsating pressure on labyrinth emitter clogging. Irrig. Sci. 2017, 35, 267-274. [CrossRef]

17. Hills, D.J.; Silveira, R.C.M.; Wallender, W.W. Oscillating pressure for improving application uniformity of spray emitters. Trans. ASABE 1986, 29, 1080-1085. [CrossRef]

18. Hills, D.J.; Gu, Y.P.; Wallender, W.W. Sprinkler uniformity for oscillating low water-pressure. Trans. ASABE 1987, 30, 729-734. [CrossRef]

19. Buchin, A.F.; Pons, S.J.; Hills, D.J.; Abudu, S. Improving Water Application Efficiency in the Landscape through Pressure Oscillation. April 2004. Available online: https://www.researchgate.net/publication/237342500 (accessed on 1 April 2019).

20. Ge, M.; Wu, P.; Zhu, D.; Ames, D.P. Comparison between sprinkler irrigation and natural rainfall based on droplet diameter. Span. J. Agric. Res. 2016, 14, 1201. [CrossRef]

21. Ge, M.S.; Wu, P.; Zhu, D.L.; Zhang, L. Analysis of kinetic energy distribution of big gun sprinkler applied to continuous moving hose-drawn traveler. Agric. Water Manag. 2018, 201, 118-132. [CrossRef]

22. Shin, S.S.; Park, S.D.; Choi, B.K. Universal power law for relationship between rainfall kinetic energy and rainfall intensity. Adv. Meteorol. 2016, 2016, 11. [CrossRef]

23. Deboer, D.W.; Beck, D.L.; Bender, A.R. A field-evaluation of low, medium, and high-pressure sprinklers. Trans. ASABE 1992, 35, 1185-1189. [CrossRef]

24. Undersander, D.J.; Marek, T.H.; Clark, R.N. Effect of nozzle type on runoff and yield of corn and sorghum under center pivot sprinkler systems. Irrig. Sci. 1985, 6, 107-116. [CrossRef]

25. DeBoer, D.; Beck, D. Field evaluation of reduced pressure sprinklers. In ASAE Paper No. 83-2024; ASAE: St. Joseph, MI, USA, 1983; p. 24.

26. Clark, G.A.; Srinivas, K.; Rogers, D.H.; Stratton, R.; Martin, V.L. Measured and simulated uniformity of low drift nozzle sprinklers. Trans. ASABE 2003, 46, 321-330. [CrossRef]

27. DeBoer, D.W.; Monnens, M.J.; Kincaid, D.C. Measurement of sprinkler droplet size. Appl. Eng. Agric. 2001, 17, 11-15. [CrossRef]

28. Yan, H.J.; Jin, H.Z.; Qian, Y.C. Characterizing center pivot irrigation with fixed spray plate sprinklers. Sci. China-Technol. Sci. 2010, 53, 1398-1405. [CrossRef]

29. Yan, H.J.; Bai, G.; He, J.Q.; Lin, G. Influence of droplet kinetic energy flux density from fixed spray-plate sprinklers on soil infiltration, runoff and sediment yield. Biosyst. Eng. 2011, 110, 213-221. [CrossRef]

30. Faci, J.M.; Salvador, R.; Playan, E.; Sourell, H. Comparison of fixed and rotating spray plate sprinklers. J. Irrig. Drain. Eng.-ASCE 2001, 127, 224-233. [CrossRef]

31. Zhang, L.; Hui, X.; Chen, J.Y. Effect of terrain slope on water distribution and application uniformity for sprinkler irrigation. Int. J. Agric. Biol. Eng. 2018, 11, 120-125. [CrossRef]

32. Thompson, A.L.; Regmi, T.P.; Ghidey, F.; Gantzer, C.; Hjelmfelt, A. Influence of kinetic energy on infiltration and erosionfluence of kinetic energy on infiltration and erosion. In Soil Erosion; American Society of Agricultural and Biological Engineers: St. Joseph, MI, USA, 2001; p. 151.

33. Ben-Hur, M.; Lado, M. Effect of soil wetting conditions on seal formation, runoff, and soil loss in arid and semiarid soils-A review. Aust. J. Soil Res. 2008, 46, 191-202. [CrossRef]

34. Gilley, J.E.; Finkner, S.C. Estimating soil detachment caused by raindrop impact. Trans. ASABE 1985, 28, 140-146. [CrossRef] 
35. Solomon, K.H. Yield related interpretations of irrigation uniformity and efficiency measures. Irrig. Sci. 1984, 5, 161-172. [CrossRef]

36. Letey, J.; Vaux, H.J.; Feinerman, E. Optimum crop water application as affected by uniformity of water infiltration. Agron. J. 1984, 76, 435-441. [CrossRef]

37. Letey, J. Irrigation uniformity as related to optimum crop production - additional research is needed. Irrig. Sci. 1985, 6, 253-263. [CrossRef]

38. Lamm, F.R.; Nelson, M.E.; Rogers, D.H. Resource Allocation in Corn Production with Water Resource Constraints; American Society of Agricultural and Biological Engineers: St. Joseph, MI, USA, 1993; Volume 9.

39. Bralts, V.F.; Pandey, S.R.; Miller, A. Energy savings and irrigation performance of a modified center pivot irrigation system. Appl. Eng. Agric. 1994, 10, 27-36. [CrossRef]

40. Mantovani, E.C.; Villalobos, F.J.; Orgaz, F.; Fereres, E. Modeling the effects of sprinkler irrigation uniformity on crop yield. Agric. Water Manag. 1995, 27, 243-257. [CrossRef]

41. Vonbernuth, R.D. Uniformity design criteria under limited water. Trans. ASABE 1983, 26, 1418-1421. [CrossRef]

42. Li, J.S.; Kawano, H. The areal distribution of soil moisture under sprinkler irrigation. Agric. Water Manag. 1996, 32, 29-36. [CrossRef]

43. Vories, E.D.; Vonbernuth, R.D. Single nozzle sprinkler performance in wind. Trans. ASABE 1986, 29, $1325-1330$. [CrossRef]

44. Ascough, G.W.; Kiker, G.A. The effect of irrigation uniformity on irrigation water requirements. Water $\mathrm{Sa}$ 2002, 28, 235-241. [CrossRef]

45. Dogan, E.; Kirnak, H.; Doyan, Z. Effect of varying the distance of collectors below a sprinkler head and travel speed on measurements of mean water depth and uniformity for a linear move irrigation sprinkler system. Biosyst. Eng. 2008, 99, 190-195. [CrossRef]

46. Dukes, M.D. Effect of wind speed and pressure on linear move irrigation system uniformity. Appl. Eng. Agric. 2006, 22, 541-548. [CrossRef]

47. Salvatierra-Bellido, B.; Montero-Martinez, J.; Perez-Urrestaraz, L. Development of an automatic test bench to assess sprinkler irrigation uniformity in different wind conditions. Comput. Electron. Agric. 2018, 151, 31-40. [CrossRef]

48. Sanchez, I.; Faci, J.M.; Zapata, N. The effects of pressure, nozzle diameter and meteorological conditions on the performance of agricultural impact sprinklers. Agric. Water Manag. 2011, 102, 13-24. [CrossRef]

49. Tarjuelo, J.M.; Montero, J.; Carrion, P.A.; Honrubia, F.T.; Calvo, M.A. Irrigation uniformity with medium size sprinklers part II: Influence of wind and other factors on water distribution. Trans. ASABE 1999, 42, 677-689. [CrossRef]

50. Tarjuelo, J.M.; Montero, J.; Honrubia, F.T.; Ortiz, J.J.; Ortega, J.F. Analysis of uniformity of sprinkle irrigation in a semi-arid area. Agric. Water Manag. 1999, 40,315-331. [CrossRef]

51. Vories, E.D.; Vonbernuth, R.D.; Mickelson, R.H. Simulating sprinkler performance in wind. J. Irrig. Drain. Eng.-ASCE 1987, 113, 119-130. [CrossRef]

52. Zapata, N.; Playan, E.; Martinez-Cob, A.; Sanchez, I.; Faci, J.M.; Lecina, S. From on-farm solid-set sprinkler irrigation design to collective irrigation network design in windy areas. Agric. Water Manag. 2007, 87, 187-199. [CrossRef]

(C) 2019 by the authors. Licensee MDPI, Basel, Switzerland. This article is an open access article distributed under the terms and conditions of the Creative Commons Attribution (CC BY) license (http://creativecommons.org/licenses/by/4.0/). 